\title{
Reflections on Strengthening the Course Teaching of Fashion Sketch
}

\author{
Jing An \\ Arts and Design School \\ Huanghe Science and Technology College \\ Zhengzhou, Henan, China, 450000
}

\begin{abstract}
The fashion sketch teaching mainly is to cultivate students' spatial design ability and expressive ability of professional design. We should respect rules and have the courage to bring forth new ideas in the teaching content and teaching method of the course. Design sketch is one of the important means to cultivate our modeling ability. It is never too much to emphasize the importance of sketching practice to design. We can improve our observation ability, aesthetic level and design level, and make eye sharp and insightful through drawing fashion sketches.
\end{abstract}

Keywords—fashion sketc; fashion drawing; fashion design

\section{INTRODUCTION}

In the fashion design of our art and design colleges and universities, professional sketch should be regarded as one of the most basic courses to our students. However, many of existing colleges and universities do not attach much weight to fashion sketch in the arrangement of courses for their students majoring in fashion design. They just arrange courses of body sketch and character sketch as preliminary practice and then directly let students enter into the learning of the professional design and fashion painting techniques. Students could not integrate basic training in painting with professional design very well and convert to professional sketch from sketching sketch naturally. As a result, a lot of students can not understand the expression of fashion design language and are affected in the professional learning.

In order to promote the improvement of teaching quality of fashion design, fashion sketch has become a course students should strengthen and take in the entire learning stage. How to do it? The paper has analyzed it in the following:

\section{UNDERSTANDING OF THE IMPORTANT ROLE OF FASHION SKETCH IN THE TEACHING OF FASHION DESIGN}

First of all, as art and design professionals all know design expression ability is one of the most important foundations in design activities. All of the creative thinking and intention need to be expressed and presented through its design language. Design sketch is one of the important means to cultivate our modeling ability. It is never too much to emphasize the importance of sketching practice to design. Therefore, students majoring in fashion design should keep drawing and draw well in order to lay a good foundation for fashion sketch.

Secondly, we can cultivate our design sensitivity and enrich our imagination through painting fashion sketches. It depends on our sensitivity and creativity to create design. We can improve our observation ability, aesthetic level and design level, and make eye sharp and insightful through painting fashion sketches.

Third, painting fashion sketch is one of the means for us to collect image data and accumulate creation materials. As we all know it is very necessary for designers to read a lot of information at ordinary times. However, it is more effective to make a sketch than look at information. When you sketch, you can observe more closely and understand more deeply. You could record details and design elements toughing you through sketch when you store many concrete images in your brain. Consequently, you can accumulate a lot of materials. Meanwhile, it also enables us to keep a watchful eye on fashion, design, brand and fashion master, helps us integrate basic training in painting with professional design as soon as possible and complete the conversion of sketching sketch, so as to improve our sketch level and increase our interest in sketch, and lay a good foundation for professional design.

Chinese well-known designer Mr. Zhang Zhaoda has ever studied fashion design in the USA. He would make hundreds of fashion sketches every day, which provides a large amount of materials for his future creation. He has repeatedly won the highest award - Golden Award in fashion. There is an old Chinese saying: "having pored over ten thousand volumes, one can write with godly power". It mainly stresses the need to practice more and think more. Only when our minds are stored with a large amount of information, can our imagination and creation burst out in the design.

\section{THE RELATIONSHIP BETWEEN FASHION SKETCH AND FASHION DRAWING}

Most fashion drawings are obtained from consolidated sketches. They are the enhanced version and improved version of fashion sketches. Many excellent designers finish their design sketch in sketch form. For example, French fashion icon Yves Saint Laurent, Christine Lacroix, Giorgio Armani and etc. draw their design sketches in sketch form. 
Japanese fashion illustrator Yajima Gong and Chang Zejie are sketch masters, and their fashion drawings are also completed in sketch form. In our country, many designers, including Wang Yutao, Fang Ying, Zou You and etc., present their design manuscripts mainly through sketches. Up to now Zou You's fashion sketch manuscripts are still a model for university students to learn and copy.

The main reason why many of our students cannot draw fashion drawing well is that they cannot master main points, including dynamic, lines and the relationship between human body and dress, in a sketch. It's not because they couldn't grasp techniques but because they practice too little. Therefore, students should strengthen practice of fashion sketch in order to draw fashion drawing well.

\section{WHAT TO DRAW IN FASHION SKETCH}

We could draw fashion sketches and find styles through a lot of channels, such as daily life, fashion conference site, videos, fashion magazines and etc..

We could draw a sketch with a pen and some paper. But there is certain difficulty to draw a sketch because of the limited conditions of some channels. The most convenient and feasible way is to find a fashion magazine. We could use it as long as there are good works regardless of the sell-by date. We could draw a sketch out of the magazine or pictorial calmly and leisurely. We could sketch no matter when without time limit. Besides, there are a variety of fashion magazines, like "Fashion Designer", "Elle", "Ruili", "Fashion", "Orient Express", which covers a lot of international fashion information. They are also urban dwellers' life guide of all aspects, including clothing, diet, housing, taste and etc.

When we draw fashion sketches, we need to capture object shape and posture as well as a series of professional characteristics, such as fashion design style, material, color, hair style, decoration and etc. We should rapidly capture and record the designer's inspiration and ideas with general and simple lines, without the pursuit of visual integrity, mainly emphasizing clothing style and effect. Sometimes we could simply use several colors to record a rough conception of color after sketching. Sometimes we can sketch with simple lines and write down a simple explanatory note to make it more convenient. We could omit the character sketch or outline it simply, mainly emphasizing certain dynamic postures, in order to show the dynamic effect of fashion. Only in this way, our training is effective, and thus we could lay a good foundation for fashion drawing and make a good preparation to improve our design level.

\section{HOW TO DRAW FASHION SKETCH WELL}

We need to pay an attention to method in the practice of fashion sketch. What is meant by method is the training rules and procedures. We must go through such a process in the study, from slow to fast, shallow to deep and simple to complex. It is also an unfamiliar-to-skilled process.

Learning any skill is nothing more than two points, professional theories and procedures. It needs a process to understand and digest a theory. Procedures are quite specific and effective, because they can guide us directly. The two points can help each other forward and reinforce each other, which requires us to think more and summary more in practice. Only in this way can we progress faster.

There are generally two basic methods to draw fashion sketches. One is composition; position with points and then draw the shape with big straight lines. Sketch the large linear form, and then depict the characters in depth. The other one is to sketch from the details; start drawing from head, face, facial features, hair, and then continue to sketch step by step. Both methods are usable. Generally beginners can use the first method. They can use the second method when they are skilled. This is the season why the fashion sketch course should be set in the whole learning stage. Only if we persist in long-term practice and constantly sum up experience of painting, can our sense of design become more mature.

We can enhance our ability and level of fashion sketch through the following ways:

\section{A. Sketching from Nature}

Students learning art and design might be not unfamiliar with sketching from nature. The drawing sketch is the basis to improve the ability of professional sketch.

It is not necessary to spend big blocks of time on sketch or to square off. One can find some time pockets and a small place to draw his/her classmates and friends, and record his/her feelings at that time. Of course, it's better to draw some interesting scenes and characters we like. One can draw a sketch when he/she find one of his/her classmates with awesome hairstyle or one of his/her friends wearing cool clothes. These distinctive things are easy to generate interest and trigger our craving to sketch. However, there is certain difficulty to draw character sketches. The model is live, so we need to organize and process all the lines. But it doesn't matter, and as long as the relations can be identified, we only have to sketch vividly. In the portrayal of characters, students should paint realistically and grasp its proportions and mien. As long as we stick to it, we can lay a good foundation for future professional fashion sketch and we will be able to draw very well.

\section{B. Copying}

Generally copying should be alternated with sketching from nature. Beginners often encounter varieties of problems in sketch. Sometimes they don't know how to draw or where to start. But it doesn't matter, and we can start from the practice of copying. Though it is a kind of indirect practice, it is definitely a good method.

You'll find out many kinds of expression styles when you copy fashion sketch. In general, it is classified into decorative style and realistic style. The decorative style mainly requires us to seize the theme of fashion design, process the design sketch properly with theatrical treatment and endow it with decorative beauty. In decorative style fashion painting, we can not only emphasize and render its theme, but also beautify the design work. We can use a 
variety of techniques to emphasize some aspects of the design, such as theatrical form, in order to highlight expression effect. The realistic style requires us to use the real effect of fashion design to draw sketch, and clearly express clothes and body details. We should master basic skills solidly and spend relatively much time on sketch, so that we could express the drawing rigorously and simply.

Gombrich said: "there is no art without traditional pattern". Some people say that the interest is a good teacher, but I say that copying is a good teacher. Copying is a stepping stone to success for beginners. We may have a look at sketch books and masterpieces of masters, or find some comics to copy and to see how to paint and process details, such as hair, the contour of face, shoulder or joint processing and folds of clothing and etc. All of these help us grasp the essentials in the future fashion sketch and express drawing vividly.

\section{Observation}

French artist Rodin said that life is not in want of beauty, but lacks the eyes that discover the beauty. We need to practice our observation ability when drawing a sketch and the observation result determines what kind of painting it is. Objective observation or overall observation is firstly required when making a sketch and the ability to make a summary and analysis is also needed.

Anyone who has a sharp observation skill can observe in a subtle way and has a quick grasp on the morphological characteristics and traits of character of subjects. For example, the relationship between the style and clothing in a fashion show is commonly well-designed by the fashion designers, and we can capture its romantic charm when drawing a sketch as long as we find something in common through careful observation.

\section{Conversion}

When drawing a fashion sketch, we should convert the drawing technique and pattern into a decorative technique or a stylized technique as far as possible. We should learn to incorporate many uncertain lines into a single line, generalize fragmentary lines to complete and smooth lines and induce a simple large straight line into a kind of decorative line. A good fashion sketch must be a sketch using integrated and simple lines to summarize highly and refine selectively the model dressed in the clothing. It should be noted that simplicity does not mean it is uncomplicated, but equals to concentration and sublimation. It implies more profound and intrinsic beauty to simplify lines than to complicate lines. A fashion sketch should not be a collection of showy lines but focusing on the representation of fabric texture and structural characteristics.

Fashion sketch often employs uniform lines, thick and thin lines and irregular lines. Uniform lines are lines with a uniform thickness which are bold, straight, clear and smooth and can be easily made with a pencil, a pen or a gel ink pen. Uniform lines are suitable to represent some light, flexible and strong fabric, such as silk, chiffon, etc., making the overall design of clothing structured, delicate and full of a strong decorative taste. The thick and thin lines, different from the uniform lines, are a combination of thick lines and thin lines which are commonly made with a brush pen or a pen or hard-tipped pen for calligraphy. The thick and thin lines coupling strength and gentleness in vivid and changeable motion are typically applicable for heavy fabric with drapability to show a strong stereoscopic impression of fashion design with ease. The irregular lines are generally evolved through learning and absorbing the lines of decorations in traditional art including stone carving, portrait brick and so on, and they are unadorned, vigorous, powerful and rhythmic. We typically use a brush pen or a marker pen to draw irregular lines to embody the fabric with uneven surface, such as various tweeds, hand-woven fabrics, etc..

The conversion of sketch lines is very useful for the completion of design renderings. Naturally, it is timeconsuming for us to transit from the reconstruction of objectiveness to the representation of objectiveness, and its effective completion requires for the integration of cultural quality, aesthetic taste and painting skill. More observation, more practice and more experience will make good results.

\section{CONCLUSION}

Fashion sketch education focuses on the development of ability of students' space design and the ability to represent their professional design, and its teaching materials and methods should be innovative according to the rules. The fashion sketch curriculum teaching should be adjusted appropriately with the deepening of educational reform and development of fashion market for the purpose of stimulating the in-depth curriculum construction, only in this way, can the characteristics of higher art education be embodied indeed and can the talent training mode suitable for social demand be established.

\section{REFERENCES}

[1] Mo Yu, Xiao Wenling. Techniques of Fashion Drawing. Shanghai: Academia Press, 2013

[2] Hao Yongqiang. Practical Techniques of Fashion Drawing. Beijing: China Textile \& Apparel Press, 2011

[3] Liu Jingyi. Presentation Techniques in Series Clothing Design. Beijing: China Youth Press, 2014

[4] Qi Xin. Quick Start Manual of Fashion Designer. Shanghai: Shanghai People's Fine Arts Publishing House, 2014 